ARTIGOS

Recebido em 21.11.2012. Aprovado em 28.06.2013

Avaliado pelo sistema double blind review. Editores Científicos: Luiz Artur Ledur Brito, Antônio Domingos Pádula e Gérson Tontini

\section{ESTILOS DE APRENDIZAGEM FELDER- SILVERMAN E O APRENDIZADO COM JOGOS DE EMPRESA}

\author{
Felder-Silverman learning styles and learning with business games \\ Estilos de aprendizaje Felder-Silverman y el aprendizaje con juegos de empresa
}

\begin{abstract}
RESUMO
O problema tratado nesta pesquisa foi a diferença de aprendizagem observada entre os estudantes de um curso de Planejamento e Controle da Produção (PCP). O objetivo foi descrever e analisar as diferenças de aprendizado segundo os Estilos de Aprendizagem (EdA). Examinaram-se a assimilação e compreensão (notas em provas) e os EdA de 356 aprendizes em 16 turmas de pós-graduação - MBA e Especialização - durante cinco anos. Um jogo de empresas dinamizou as vivências nas quais observou-se maior aprendizado dos estudantes com estilo reflexivo (ativo-reflexivo) ou visual (visualverbal). Ao não explorar a reflexão, o jogo pode ter restringido o ciclo de aprendizagem vivencial, sobretudo dos ativos. Sugerem-se aos educadores duas diretrizes para o desenho educacional: quando padronizado, que se busque balancear as atividades para atender aos diferentes EdA. Quando 0 desenho for personalizado, que se insiram atividades complementares às preferências do aprendiz, viabilizando uma vivência com equilíbrio entre ação e reflexão.
\end{abstract}

PALAVRAS-CHAVE | Ensino e aprendizagem, aprendizagem vivencial, estilos de aprendizagem, jogos de empresa, MRPII.

\begin{abstract}
The problem this study dealt with was the difference in learning observed among students of a Production Control and Planning (PCP) course. The objective was to describe and to analyze the learning differences according to Learning Styles (LS). Assimilation and comprehension (test scores) and the $L S$ of 356 students in 16 graduate classes - MBAs and Extension Courses - from five years were examined. A business game brought the experiences to life, where greater learning was observed among students with a reflective (active-reflective) or visual (visual-verbal) style. By not exploring reflection, the game may have restricted the experience learning cycle, especially among the active ones. Two guidelines for the educational design are suggested for educators: when standardizing the designone should seek to balance activities in order to meet different LS. When the design is personalized, one should insert activities which are complementary to the learner's preferences, thus enabling a balanced experience between action and reflection.
\end{abstract}

KEYWORDS / Teaching and learning, experience learning, learning styles, business games, MRPII.

\section{RESUMEN}

El problema tratado en esta pesquisa fue la diferencia de aprendizaje observada entre los estudiantes de un curso de Planificación y Control de la producción (PCP). El objetivo fue describir y analizar las diferencias de aprendizaje según los Estilos de aprendizaje (EdA). Se examinaron la asimilación y la comprensión (notas en pruebas) y los EdA de 356 aprendices en 16 grupos de postgrado -MBA y Especialización-durante cinco años. Un grupo de empresas dinamizó las vivencias en las cuales se observó un mayor aprendizaje de los estudiantes con estilo reflexivo (activo-reflexivo) o visual (visualverbal). Al no explotar la reflexión el juego puede haber restringido el ciclo de aprendizaje vivencial, sobretodo de los activos. Se sugiere a los educadores dos directivas para el diseño educacional: cuando sea estandarizado y se busque balancear las actividades para atender a los diferentes EdA. Cuando el diseño fuera personalizado, que se incluyan actividades complementarias a las preferencias del aprendiz, viabilizando una vivencia con equilibrio entre la acción y la reflexión.

PALABRAS-CLAVE / Enseñanza y aprendizaje, aprendizaje vivencial, estilos de aprendizaje, juegos de empresa, MRPII. 


\section{INTRODUÇÃO}

A inovação acelerada tem alterado diversas áreas da atividade humana. Alguns setores, entretanto, apresentam desafios e resistências mais difíceis de serem transpostos. As Instituições de Ensino Superior (IES), por exemplo, resistem em transformarse em Instituições Superiores de Aprendizagem. Os estudantes que hoje chegam à universidade estavam na infância em 2005, quando a internet de banda larga ultrapassou a conexão discada no Brasil. Em poucos anos, a universidade estará recebendo pessoas que cresceram relacionando-se pelas redes sociais da internet. Eles toleram cada vez menos o processo educacional com foco no ensino e protagonismo do professor.

O ensino superior mudou e precisa mudar mais. A prática de ensino em que o estudante tem uma postura passiva e observadora em aulas predominantemente expositivas é inviável. No momento em que vemos nascer e proliferar os Massive Open Online Courses (MOOCs), produzidos nas melhores universidades do mundo (inclusive brasileiras), a atividade didática centrada na exposição de conteúdo, sem o diálogo com o aprendiz, não se justifica, seja por sua ineficácia ou ineficiência. Com a utilização complementar de recursos como os MOOCs, os agentes de aprendizagem terão mais tempo e recursos para investir em outros tipos de atividades que gerem mais engajamento dos estudantes.

Vivemos a era da informação e da personalização de produtos e serviços, entretanto isso ainda é raro no processo educacional. Os meios de produção de produtos e serviços hoje disponíveis levaram a personalização a um nível que dificulta a escolha para alguns consumidores, tamanha a quantidade de alternativas e opcionais. Para Schwahn e McGarvey (2012), a atividade educacional não pode esperar sobreviver, posicionando-se como uma ilha, abraçada à Era Industrial, da produção em massa. Atualmente, a regra, nos cursos e disciplinas do ensino superior, é oferecer sempre o mesmo processo de aprendizagem, com o mesmo conteúdo, os mesmos exercícios para todos os estudantes, independentemente de seus talentos, interesses e desinteresses pessoais, pontos fortes, fracos ou seus estilos de aprendizagem (EdA).

Mas será que todos aprendem da mesma forma? Quando adotado um método de ensino, pode-se esperar assimetria no aprendizado, dependendo do EdA do aprendiz? Diante dessa problemática, algumas questões passaram a motivar pesquisadores e professores na busca pelo aprimoramento do processo de aprendizagem.

Diante da evidência de aprendizagem assimétrica, observada em disciplinas de Planejamento e Controle da Produção (PCP) ministradas entre 2008 e 2012, buscou-se formular um desenho de pesquisa que permitisse explicar quais EdA puderam se favorecer com o processo de aprendizagem apoiado por jogos de empresas.

No quadro teórico deste estudo, são apresentados os desafios focalizados na aprendizagem dos conceitos de planejamento com apoio de sistemas de administração da produção. A teoria de aprendizagem vivencial é apresentada, pois tem papel central para interpretação dos resultados da pesquisa. Em especial, a didática suportada pelos jogos é explorada com a apresentação de uma teoria adaptada de aprendizagem vivencial para processos educacionais mediados por jogos de empresa.

A teoria dos modelos de EdA é apresentada e também tem papel central para coleta e discussão dos resultados, na medida em que o estudo procurou identificar as diferenças de aprendizado segundo os EdA dos estudantes. Neste estudo, foi utilizado o modelo de EdA de Felder e Silverman (1988), denominado Index of Learning Styles (ILS).

\section{SISTEMAS INTEGRADOS DE GESTÃO (MRPII/ERP)}

Em um sistema Enterprise Resource Planning (ERP), pretende-se suportar a necessidade de informação para tomada de decisão gerencial da empresa como um todo. Para Koh, Gunasekaran e Rajkumar (2008), a utilização efetiva de um sistema ERP tem sido uma das alternativas escolhidas por empresas na busca de vantagens competitivas. Entretanto, o processo de implantação do ERP é desafiador. Para esse ambiente de implantação, Corrêa (1999) apontou a falha das aulas expositivas e treinamentos do software, por duas razões: por um lado, não permitem que se vivencie o gerenciamento das operações com a dinâmica e as relações temporais das decisões; por outro lado, a utilização do software real eleva demasiadamente a complexidade e prejudica o entendimento dos conceitos. No esquema geral do MRPII, há uma série de tomadas de decisão que se sucede a cada ciclo de planejamento. 0 autor sugeriu a utilização de ferramentas de simulação concebidas especificamente para o processo didático.

A ferramenta de treinamento adequada deveria ter uma complexidade intermediária entre os exercícios dados em aula e a simulação de operação do próprio software. Isto só pode ser obtido com um exercício que seja suficientemente complexo para simular todos os principais aspectos e decisões que um sistema MRPII/ERP real apresenta e, ao mesmo tempo, simples o su- 
ficiente para permitir um aprendizado mais rápido. (CORRÊA, 1999, p. 2)

Um dos componentes centrais dos sistemas MRPII é o registro básico do MRP, exemplificado na Figura 1. Segundo Corrêa, Gianesi e Caon (2007), é importante que sua mecânica seja entendida perfeitamente, pois ele é a interface essencial entre o sistema de administração da produção e seus usuários. A capacitação de profissionais para assumirem a gestão de operações e comandá-las a partir de um sistema ERP demanda treinamento intensivo e continuado em todos os níveis das organizações. O método a ser empregado para preparar os profissionais tem importância, pois sua eficácia pode determinar em que medida os investimentos feitos pela organização serão transformados em benefícios com o uso efetivo do sistema.

Figura 1. Exemplo de registro básico do MRP

\begin{tabular}{|l|c|c|c|c|c|c|c|c|}
\hline $\begin{array}{l}\text { Miolo Interno I } \\
\text { Períodos=3 }\end{array}$ & 1 & 2 & 3 & 4 & 5 & 6 & 7 & 8 \\
\hline $\begin{array}{l}\text { Necessidades Brutas } \\
\text { Recebimentos }\end{array}$ & 100 & 20 & & 80 & 120 & & 70 & 150 \\
\hline $\begin{array}{l}\text { Programados } \\
\text { Estoque } \\
\text { Disponível }\end{array}$ & 50 & 30 & 130 & 50 & 0 & 0 & 0 & 0 \\
\hline $\begin{array}{l}\text { Chegada de Ordens } \\
\text { Planejadas }\end{array}$ & & 100 & & & 70 & & 70 & 150 \\
\hline $\begin{array}{l}\text { Plano de Liberação } \\
\text { de Ordens }\end{array}$ & 70 & & 70 & 150 & & & \\
\hline
\end{tabular}

Fonte: CORRÊA, GIANESI, CAON, 2007.

\section{APRENDIZAGEM VIVENCIAL E ESTILOS DE APRENDIZAGEM (EdA)}

Kolb (1984) formulou uma teoria integradora de aprendizagem vivencial que se sustenta principalmente na educação progressiva de John Dewey, na teoria de dinâmica de grupo (T-groups), na pesquisa ação de Kurt Lewin e na tradição de desenvolvimento cognitivo de Piaget e seus seguidores, voltados para esse desenvolvimento na vida adulta (Figura 2).

Dewey (1938) opôs-se às ideias a respeito das práticas educativas convencionais, com uma abordagem denominada por ele como progressiva, em que valorizava o cultivo da individualidade, a aprendizagem por meio da experiência e a aquisição de habilidades e técnicas como meio de alcançar resultados que fazem uso direto dessas habilidades e técnicas. "Creio que a unidade fundamental da nova filosofia é encontrada na ideia de que existe uma relação íntima e necessária entre os processos de experiência real e educação" (DEWEY, 1938, p. 6).

\section{Figura 2. Base teórica do modelo de aprendizagem vivencial de Kolb (1984) e do modelo de estilos de aprendizagem (EdA) de Felder e Silverman (1988)}

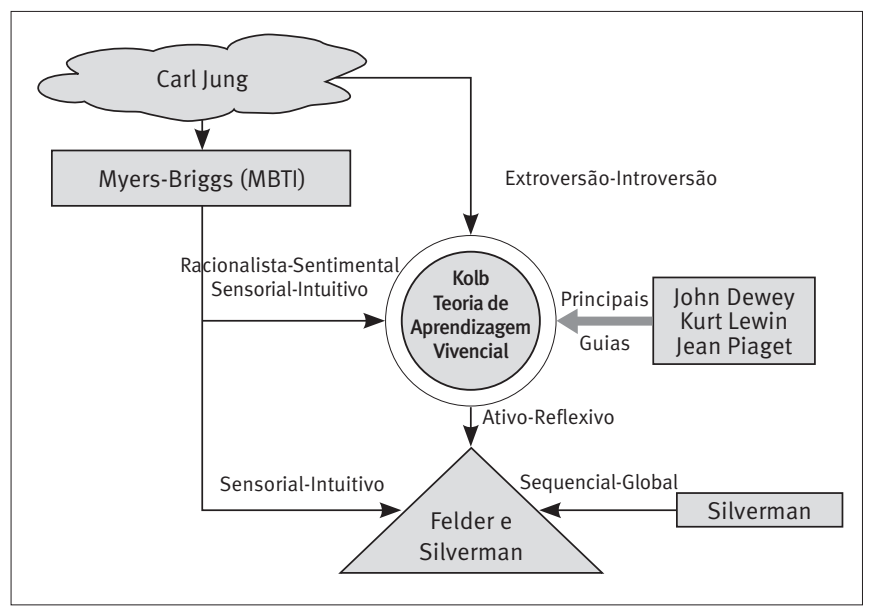

Kolb (1984, p. 8) fundamenta-se nos processos de aprendizagem propostos por: i) Dewey, que coloca a experiência no ponto de partida, seguida pela revisão e generalização, que, então, devem ser testadas na prática, com novas experiências, e ii) Lewin, que também sugere um processo de aprendizagem, mas com cinco etapas sucessivas abstração, implicação concreta, experiência, observação-feedback e reflexão. Kolb (1984, p. 8) declara, ainda, ter usado como fundamento o T-group descoberto por Lewin (ou cujas constatações permitiram o desenvolvimento) em 1947: “O aprendizado é mais bem facilitado num ambiente em que haja uma tensão dialética e conflito entre a imediata experiência concreta e o distanciamento analítico".

A contribuição distinta dos achados de Piaget está em sua descrição do processo de aprendizagem como uma dialética entre a assimilação das experiências em conceitos e a acomodação dos conceitos na experiência e seu trabalho na epistemologia - a relação entre a estrutura do conhecimento e como ele é aprendido (KOLB, 1984, p. 18).

Na visão proposta por Kolb (1984, p. 38, tradução nossa), “a aprendizagem é o processo pelo qual o conhecimento é criado por meio da transformação da vivência”. Mintzberg e Gosling (2003, p. 32), ao apresentarem sua experiência de aprendizagem vivencial com a criação e implementação do International Masters Program in Practicing Management (IMPM), destacaram ter observado que o processo de aprendizagem é mais eficiente quando conecta ideias às experiências vividas. Ressal- 
taram, também, que o papel dos professores é alavancar esse processo, e não preencher os estudantes com conhecimento.

No modelo de aprendizagem vivencial consolidado por Kolb (1984), a construção do conhecimento caracteriza-se pela repetição combinada e cíclica das ações de captação e transformação da vivência. Segundo ele, a aprendizagem só ocorre se percorridas todas as etapas de um ciclo.

A ideia central aqui é que a aprendizagem e, portanto, o saber requer uma captação ou representação figurativa da vivência e alguma transformação dessa representação. A captação figurativa ou a transformação operativa sozinha não é suficiente. A simples percepção da vivência não é suficiente para a aprendizagem; algo deve ser feito com ela. Da mesma forma, a transformação sozinha não pode representar aprendizagem, pois deve haver algo a ser transformado, algum estado ou vivência que esteja em curso. (KOLB, 1984, p. 42, tradução nossa)

Na dimensão de preensão (ato de agarrar) do conhecimento, estão as etapas em que o sujeito capta e se apropria da sua vivência:

- A “vivência concreta" baseia-se nas características tangíveis, sentidas durante a vivência. Ela depende dos sentidos e do nível de imersão na realidade concreta da vivência. Esse tipo de atividade leva ao conhecimento imediato por meio da percepção, memória ou julgamento de algo relativamente simples e que resulta na sua presença na consciência (apreensão).

- A “conceitualização abstrata” depende da interpretação conceitual e da representação simbólica da vivência. Ela está associada ao conhecimento obtido pela formação de conceitos, construção teórica e análise da vivência (compreensão).

Já na dimensão de transformação da vivência, que leva o sujeito à criação de significado para o que foi captado na vivência, há dois tipos de ação de transformação:

- A “observação reflexiva”, em que o exame ou manipulação da informação ocorre de uma forma introspectiva, no mundo das ideias, com o intento de transformar o conhecimento resultante das apreensões.

- A “experimentação ativa”, em que acontecem atividades no mundo físico que trazem significado para aquilo que já foi compreendido pelo sujeito do aprendizado.

A dimensão de transformação da vivência pode ser melhor descrita pela teoria de tipos psicológicos de Carl Jung (Figura 2). A “observação reflexiva” relaciona-se com o conceito de introversão, em que o sujeito (subjectu) é sempre privilegiado em relação ao objeto. No extremo oposto, a "experimentação ativa" é representada pela extroversão, em que os processos objetivos são sempre mais valorizados do que os subjetivos.

A relação da teoria de aprendizagem vivencial com os tipos psicológicos de Jung abrange, também, dimensão de preensão (ou captação) do conhecimento. Kolb (1984, p. 80) apresentou previsões conceituais e evidências empíricas de que as percepções da "vivência concreta" estão associadas com as abordagens de sensação e de sentimento dos tipos psicológicos de Jung, enquanto as compreensões provenientes da "conceitualização abstrata" relacionam-se com a intuição e o pensamento.

Kayes (2002) valorizou a teoria de aprendizagem vivencial de Kolb (1984) ao apresentar um paralelo entre suas dimensões fundamentais (vivência concreta, observação reflexiva, conceitualização abstrata, experimentação ativa) e quatro dimensões epistemológicas da teoria de aprendizagem gerencial (ação, cognição, reflexão e experiência). Entretanto, criticou-a, por avaliar como pequena a atenção dispensada à relação entre conhecimento pessoal (tácito) e social (explícito). Ele propôs um novo quadro conceitual que preservou a natureza dialética da vivência, mas que levou em conta os aspectos sociais, sugerindo maior ênfase à linguagem e ao diálogo no processo de aprendizagem gerencial.

Outra evolução da teoria de aprendizagem vivencial de Kolb foi proposta por Sauaia (2010, p. XIX) para o contexto específico do laboratório de gestão (simulador organizacional, jogo de empresas e pesquisa aplicada). Nessa adaptação, ilustrada pela Figura 3, as etapas definidas conceitualmente por Kolb (1984) são traduzidas nas ações que compõem a vivência dos aprendizes durante a realização de um jogo de empresas: avaliação dos resultados, discussão com base nas teorias, revisão do plano de gestão e tomada de decisão.

\section{Figura 3. Ciclo de aprendizagem vivencial}

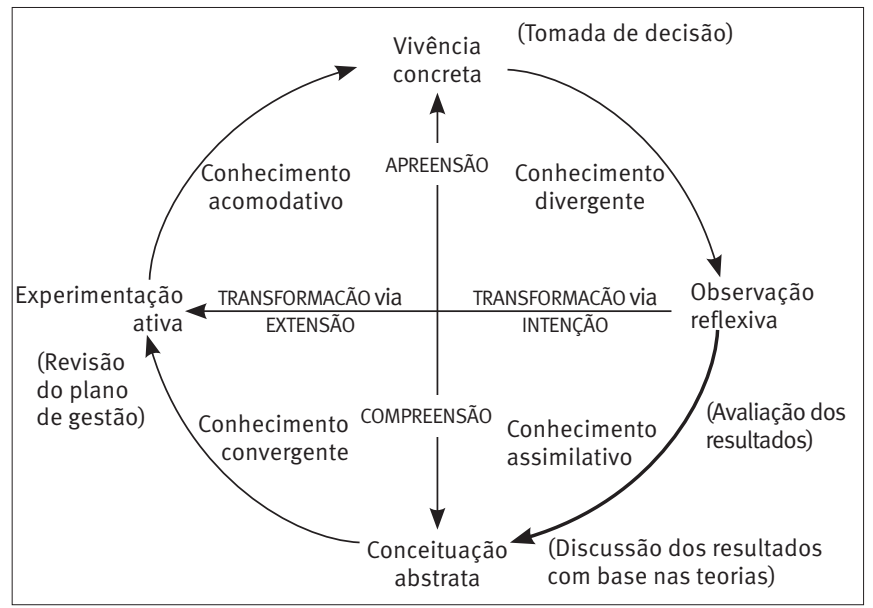

Fonte: SAUAIA, 2010 
O modelo estrutural de aprendizagem vivencial é a base de uma tipologia de EdA. Seno e Belhot (2009, p. 6) observaram, em seus estudos, aspectos do comportamento de aprendizes focalizando seus EdA.

Os indivíduos possuem diferentes maneiras de perceberem e processarem as informações, alguns estudantes têm sua atenção voltada mais para fatos e dados, enquanto outros gostam mais de teorias e modelos matemáticos. Alguns respondem positivamente às informações visuais, como figuras, diagramas e esquemas; outros preferem as formas verbais - explicações faladas e escritas. Existem ainda os que preferem aprender ativamente com a prática, enquanto outros aprendem de forma individual e introspectiva. [...] Quando há uma falta de sintonia entre os estilos de aprendizagem e os estilos de ensino, resultados desastrosos podem ser obtidos. (SENO e BELHOT, 2009, p. 6)

Felder e Silverman (1988, p. 674) sintetizaram o aprendizado em um processo de duas etapas: 1) a recepção de informações e 2) o processamento de informações. Seu modelo de EdA propôs-se a identificar as formas como os aprendizes preferencialmente recebem e processam as informações. Esse modelo foi apresentado conjuntamente com os estilos de ensino normalmente presentes em cursos de Engenharia. A origem do modelo de EdA de Felder e Silverman (1988), como ilustrado na Figura 2, baseou-se nos EdA de Kolb (1984) e nos tipos psicológicos incorporados pelo Myers-Briggs Type Indicator (MBTI). Os EdA propostos na revisão de 2002 do modelo organizam-se em quatro dimensões de preferências:

1. Sensorial-intuitivo: definição emprestada da teoria de tipos psicológicos de Jung presente no MBTI que descreve as formas como as pessoas percebem o que ocorre ao seu redor. Os aprendizes sensoriais preferem lidar com fatos e dados e, geralmente, preferem aprender pela experimentação. Foram descritos por Felder e Silverman (1988) como detalhistas, enquanto os intuitivos, em geral, são mais rápidos e menos atentos aos detalhes e preferem lidar com princípios e teorias.

2. Visual-verbal: o visual foi descrito como aquele que meIhor memoriza o que vê em figuras, diagramas, fluxogramas, filmes e demonstrações. 0 verbal prefere que, durante a aprendizagem, as informações sejam ditas ou escritas.

3. Ativo-reflexivo: relaciona-se com o processo mental pelo qual as informações percebidas são convertidas em co- nhecimento e baseia-se na dimensão das atividades de transformação do ciclo de Kolb (experimentação ativa e observação reflexiva). Os ativos são mais atraídos pela possibilidade de experimentar ideias e participar de atividades sociais, como discussões ou explicações em grupo. Para os reflexivos, além do pensamento e da reflexão, é ainda mais importante a possibilidade de trabaIhar individualmente (GRAF e outros, 2007).

4. Sequencial-geral: classifica a forma como se aborda um novo assunto, seja pelo encadeamento sequencial e lógico ou por uma ideia ampla e geral do que será aprendido. Os sequenciais aprendem melhor quando o material é apresentado de maneira encadeada numa progressão de dificuldade e complexidade. Os gerais, entretanto, não conseguem aprender dessa forma, eles ficam perdidos por várias semanas enquanto uma disciplina evolui, até que, de repente, tudo parece fazer sentido para eles, como se as peças de um quebra-cabeças se encaixassem simultaneamente. Os sequenciais conseguem trabalhar com conteúdo enquanto sua compreensão é parcial ou superficial; os gerais, não.

\section{Figura 4. Escala de resultados do ILS}

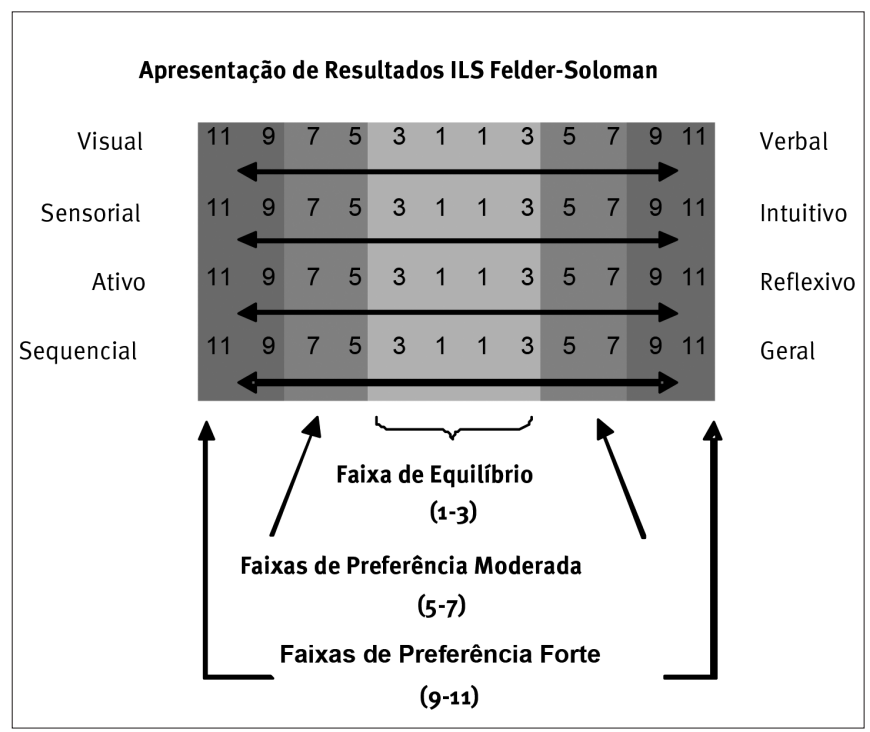

Fonte: FELDER, SOLOMAN, 1991.

O Quadro 1 apresenta características dos aprendizes segundo seu EdA. O Index of Learning Styles Questionnaire (ILS) é um instrumento on-line usado para avaliar preferências nas quatro dimensões do modelo de EdA formuladas por Richard M. Felder e Linda K. Silverman (Felder-Silverman). O questionário foi desenvolvido por Richard M. Felder e Barbara A. Soloman (ILS-Felder-Soloman). 


\section{Quadro 1. Características dos aprendizes de acordo com seu estilo de aprendizagem}

\begin{tabular}{|c|c|c|}
\hline CARACTERÍSTICA & SENSORIAL & INTUITIVO \\
\hline Fontes preferidas de dados & Fatos, dados e experimentações & Princípio e teorias \\
\hline Método preferido de solução de problemas & Padronizados e sem surpresas & Com inovação e sem repetição \\
\hline Relação com complicações & Procuram evitar complicações & Recebem bem as complicações \\
\hline Habilidades específicas & Têm habilidade para memorizar fatos & Bons para captar novos conceitos \\
\hline Velocidade $x$ Atenção & Cuidadosos, mas podem ser lentos & Rápidos, mas podem ser descuidados \\
\hline Relações sociais no aprendizado & Trabalham bem em grupo & Trabalham melhor sozinhos ou em duplas \\
\hline Características de destaque & Tendem a serem experimentalistas & Tendem a serem teóricos \\
\hline CARACTERÍSTICA & VISUAL & VERBAL \\
\hline Retenção do aprendizado & $\begin{array}{l}\text { Lembram melhor as coisas que veem, como } \\
\text { figuras, diagramas, esquemas, filmes e } \\
\text { demonstrações }\end{array}$ & $\begin{array}{l}\text { Lembram-se muito do que ouvem e ainda } \\
\text { mais do que ouvem e falam }\end{array}$ \\
\hline Método preferido de solução de problema & Passo a passo & $\begin{array}{l}\text { Fazem saltos intuitivos durante a solução de } \\
\text { problemas }\end{array}$ \\
\hline $\begin{array}{l}\text { Trabalham com material de que tenham } \\
\text { entendimento parcial }\end{array}$ & Sim & Com grande dificuldade \\
\hline Habilidade de destaque & Capacidade de análise & $\begin{array}{l}\text { Capacidade de síntese } \\
\text { Pesquisadores multidisciplinares }\end{array}$ \\
\hline Características de destaque & & Dificuldade na escola tradicional \\
\hline
\end{tabular}

Fonte: FELDER e SILVERMAN, 1988.

Os quatro EdA são avaliados por meio do ILS, um questionário individual em que se define uma nota numa escala bipolar de 12 pontos para cada EdA, como ilustrado na Figura 4. Há três faixas para cada EdA:

- $\quad 0$ resultado um ou três indica não haver preferência;

- O resultado cinco ou sete indica preferência moderada. Nesse caso o aprendiz deve aprender com mais facilidade num ambiente de ensino que favoreça o EdA;

- O resultado 9 ou 11 indica preferência forte no EdA. 0 aprendiz pode ter dificuldades de aprendizado em ambiente que desconsidere esse EdA. 


\section{CONTRIBUIÇÃO DOS MODELOS DE ESTILOS DE APRENDIZAGEM}

Apesar da abundante diversidade teórica a respeito dos EdA, o valor da sua aplicação prática está longe de ser consenso. Pashler e outros (2008), por exemplo, apontaram o desenvolvimento de uma próspera indústria de EdA e questionaram sua popularidade na educação, indicando falta de evidências robustas de validade para sua utilização.

Os modelos de EdA baseiam-se na busca de diferenças individuais e derivam de referências teóricas variadas. Coffield e outros (2004, p. 145, tradução nossa) apresentaram uma ampla revisão de modelos de EdA com base na análise de 71 modelos (com sete atualizações), publicados entre 1909 e 2003. Registraram três críticas principais: i) condenaram as "fortunas que estão sendo construídas enquanto instrumentos, manuais, vídeos, pacotes de serviço, publicações e workshops são promovidos pelas principais figuras do campo"; ii) questionaram a falta de uniformidade e coordenação dos desenvolvedores das dezenas de modelos publicados sem que alguma pessoa ou organização responsabilize-se pela supervisão ou para recomendar mudanças; iii) apontaram para o perigo do uso empírico e sem base teórica dos modelos. Por outro lado, também mostram recomendações positivas para o uso de alguns modelos de EdA que, na sua avaliação, mostraram-se mais robustos e válidos.

Curry (1990) somou três críticas à pesquisa de EdA: i) a confusão conceitual entre estilos, estratégias e táticas de aprendizagem; ii) a falta de confiabilidade e validade de medidas; e iii) a falha na identificação de características relevantes das configurações de aprendizagem e ensino.

Estudos a respeito da confiabilidade e validade interna do EdA apresentaram diferentes resultados. Litzinger e outros (2007) conduziram estudo psicométrico do ILS e apontaram resultados aceitáveis quanto a sua confiabilidade e evidências da validade do seu construto. Van Zwanenberg, Wilkinson e Anderson (2000), em estudo comparativo do ILS com outro modelo de EdA, apresentaram resultados comparativos de menor validade interna para o ILS. Felder e Spurlin (2005) consolidaram os resultados de pesquisas sobre o ILS que comprovassem: i) a confiabilidade com testes replicados, ii) a consistência interna, iii) a ortogonalidade das entre as dimensões e iv) a validade de construto.

Felder (2010) apontou que os críticos dos EdA fundamentam seus argumentos no que chamou de meshing hypothesis. Segundo essa hipótese, deveria haver entrosamento entre o EdA do aprendiz e o desenho instrucional da disciplina. Ele contra-argumenta que a utilização principal dos EdA deveria ser o desenvolvimento de disciplinas mais balanceadas, sem o favorecimento de um EdA ou outro. Durante a apresentação dos resultados do estudo realizado por Felder e Spurlin (2005), reafirmou-se que o principal propósito do estudo dos EdA é o desenho instrucional balanceado para o atendimento dos diferentes EdA.

Apesar do posicionamento crítico de Felder (2010) ao meshing hypothesis, existem estudos que procuram identificar benefícios da combinação dos EdA com o método de ensino adotado. Silva (2006), em pesquisa feita com estudantes de graduação em Contabilidade, mediu o desempenho acadêmico segundo o EdA do estudante, do professor e o estilo da disciplina. Ela encontrou diferenças para alguns fatores tratados individualmente e quando combinados. Para a dimensão ativo-reflexivo, os melhores desempenhos aconteceram quando a disciplina era ativa e o estudante e professor, reflexivos. Dias, Sauaia e Yoshizaki (2008), em levantamento com pequeno grupo de estudantes de pós-graduação em Administração, identificaram os reflexivos com melhor desempenho nos jogos de empresa. Cook e outros (2009) estudaram a aprendizagem mediada pela internet para avaliar a diferença de aprendizagem de estudantes de Medicina na busca de relação entre a dimensão sensorial-intuitiva e diferentes relações de precedência entre a apresentação de conceitos e os exercícios. Seus resultados não mostraram diferenças significativas. Hsieh e outros (2011) avaliaram o aprendizado de estudantes do quinto ano do ensino básico segundo sua preferência ativa-reflexiva e o estilo da disciplina. Eles identificaram que, quando a atividade reflexiva era mais adequada ao EdA dos estudantes, o aprendizado foi superior.

\section{JOGOS DE EMPRESA}

Com o desenvolvimento da informática, na década de 1950, surgiram simuladores para o apoio didático. Isso permitiu o desenho de experiências de aprendizagem para condução de vivências denominadas jogos de empresa. Keys e Biggs (1990, p. 49) classificaram os jogos de empresa em dois tipos. De um lado, os total enterprise games exigem decisões conjuntas da maior parte das áreas da empresa: marketing, produção, finanças e gestão de pessoal. Do outro lado, os jogos funcionais priorizam as decisões numa determinada área funcional da empresa.

Segundo Sauaia (2006, p. 8), os jogos de empresa representam um método educacional que provê uma dinâmica vivencial similar à realidade de uma empresa. É possível, por meio de um laboratório de gestão, propiciar uma vivência para que os aprendizes aprendam enquanto fazem. Os jogos de empre- 
sas geram feedback imediato sobre a qualidade das ações dos seus gestores, tanto para estes como para o professor, que percebe imediatamente o que já foi entendido e o que ainda não foi. Essa característica também foi destacada por Sugar e Whitcomb (2006, p. 2) como qualidade importante dos jogos de empresas como ferramenta educacional.

Na evolução do conceito de aplicação dos jogos de empresa, Sauaia (2010, p. XVII) definiu o laboratório de gestão como ambiente de educação gerencial e pesquisa. Nominou três pilares conceituais: i) o simulador organizacional é o elemento tangível representado pelas regras econômicas descritas no caso empresarial, ii) o jogo de empresas é o elemento intangível que constitui um processo de tomada de decisão em um ambiente de incerteza, assimetrias e competição, como ilustrado pela Figura 5, e iii) a pesquisa aplicada permite ao estudante, já na graduação, registrar, na forma de um artigo científico, sua vivência como protagonista de um processo de gestão empresarial e de criação de conhecimento.

\section{Figura 5. Componentes dos jogos de empresa}

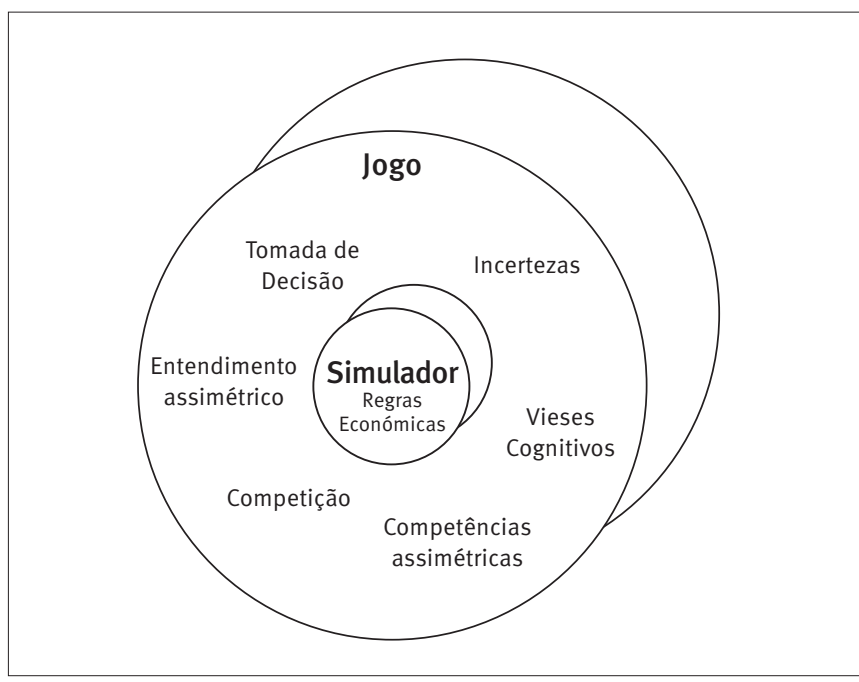

Fonte: SAUAIA, 2010.

Faria (2001) revisou a evolução das pesquisas em jogos de empresas no período de 1975 a 2001. O estudo foi desenvolvido com base nos artigos publicados na Association for Business Simulation and Experiential Learning (ABSEL). Identificou as seguintes subáreas:

a. Fatores determinantes do desempenho dos jogos de empresa: determinação dos fatores que levam ao bom desempenho nos jogos;

b. Eficácia e eficiência dos jogos;

c. O que é ensinado com os jogos: habilidades que podem ser aprendidas com a adoção dos jogos de empre- sa e, posteriormente, o estudo de como esse aprendizado acontece.

Como apontado por Sauaia (1995, p. 243), a respeito do papel dos jogos de empresa no processo educacional, acredita-se que eles não devem tomar o lugar de outros métodos educacionais, mas complementá-los para suprirem as conhecidas, e não equacionadas, deficiências na educação convencional. Contudo, a adoção dos jogos apresenta desafios, como destacaram Paes de Paula e Rodrigues (2006), que adotaram métodos de aprendizagem centrados no aprendiz, mas enfrentaram reação negativa dos estudantes. Tal reação estaria associada à expectativa por uma pedagogia tradicional, sugerindo que os aprendizes acham-se condicionados pela abordagem disciplinar a esperarem dos cursos e dos docentes soluções prontas e respostas inquestionáveis. Segundo eles, os estudantes sentem-se inseguros e ansiosos quando são retiradas as prescrições de soluções mágicas oferecidas pelos professores.

\section{PROBLEMA DE PESQUISA E OBJETIVO DO ESTUDO}

O problema central da pesquisa reside nas diferenças de aprendizagem, mais especificamente na compreensão dos conceitos do MRP, MRPII e ERP decorrente dos diferentes EdA dos estudantes, em especial quando adotado um jogo de empresa.

\section{MÉTODO DE PESQUISA}

Desenvolveu-se um estudo descritivo bibliográfico baseado em fontes secundárias (livros, teses e artigos) e na coleta de dados primários durante a condução de oito turmas da disciplina de Gestão da Produção e Estoques e oito turmas da disciplina Planejamento, Programação e Controle de Operações, respectivamente nos cursos de Especialização em Logística Empresarial (400 horas de carga) e MBA Executivo Gestão de Operações Produtos e Serviços ( 435 horas de carga). Esse relatório de pesquisa orientou-se pelo modelo da monografia racional proposto por Sauaia (1996).

Nas disciplinas em questão, utilizou-se um simulador funcional (Itec) e um jogo de empresas (Politron-Internet) desenvolvidos para o ensino de planejamento da produção com sistemas MRPII-ERP e estratégia de operações. O jogo, criado no início da década de 1990, reúne mais de 4 mil participantes em cursos de pós-graduação e treinamentos corporativos. Para essa pesquisa, foram coletados dados primários entre 2008 e 2012. 
O levantamento conduzido na pesquisa fundamentou-se em dados dos aprendizes:

1. EdA medido pelo ILS;

2. Desempenho no teste de conhecimento aplicado no final do curso.

Os dados de aproveitamento no teste de conhecimento foram submetidos a análises de variância (ANOVA) para cada $E d A$, com objetivo de identificar diferenças aprendizado segundo os EdA.

A escolha do ILS foi feita, primeiramente, por conta de sua relação com o modelo de aprendizagem vivencial de Kolb (1984). Em segundo lugar, foi uma escolha por conveniência, na medida em que a ferramenta é distribuída gratuitamente pela internet. Um terceiro motivo que influenciou essa escolha foi o fato de a pesquisa ter sido conduzida numa escola de Engenharia e o ILS ter sido concebido originalmente para utilização com estudantes de Engenharia.

\section{DESCRIÇÃO DO ESTUDO E COLETA DE DADOS}

A coleta de dados secundários deu-se por meio de revisão de literatura especializada em aprendizagem vivencial, jogos de empresa e EdA. Os dados primários que compuseram esse estudo vieram do levantamento das preferências de aprendizagem de acordo com o modelo de EdA proposto por Felder e Silverman (1988) e do aprendizado dos estudantes medido em questões a respeito da lógica do MRP, do MRPII e dos sistemas ERP, resolvidas pelos 356 aprendizes como parte de uma prova objetiva de final de curso.

Durante os cinco anos de coleta, formaram-se 111 equipes gerenciais, das quais 30 faliram suas empresas após três ciclos de gestão. Nesse momento, após a aprendizagem inicial do funcionamento da empresa, impôs-se no jogo a diminuição do número de empresas, permitindo ao professor dedicar mais tempo a cada um dos grupos.

No início de cada disciplina, os aprendizes responderam ao questionário do ILS para identificação de seus EdA. Para o curso de Logística, a disciplina foi ministrada em nove aulas semanais de 200 minutos. No MBA, foram seis aulas de 240 minutos. Parte das atividades ocorreu fora da sala de aula, apoiada no site do jogo. Do tempo investido em aula, os aprendizes dedicaram aproximadamente $70 \%$ às atividades de gestão da empresa e 30\% para assistirem a exposição de conceitos. Nas duas primeiras aulas, foram apresentados os conceitos básicos de administração de produção, bem como o registro do MRP. Nas aulas seguintes, sucederam-se conceitos como Sales and Operations Planning (S\&OP) ou Planejamento de Vendas e Operações, Previsão de Vendas, MRPII e Acurácia de Dados (Quadro 2). Na disciplina do curso MBA, as aulas 5 e 6 foram fundidas em uma, a aula 7 foi suprimida e as aulas 8 e 9 foram unificadas.

\section{Quadro 2. Estrutura da disciplina no curso de logística empresarial}

\begin{tabular}{l} 
Aula 01 - Sistemas de Administração da Produção \\
\hline Aula 02 - Estudo de Caso e MRP \\
\hline Aula 03 - S\&OP - Sales and Operations Planning \\
\hline Aula 04 - Previsão de Vendas \\
\hline Aula 05 - Dinâmica de Consultoria \\
\hline Aula 06 - De MRP para MRP II \\
\hline Aula 07 - Acurácia de Dados \\
\hline Aula 08 - Apresentação dos Resultados para o Conselho \\
\hline Aula 09 - Discussão aberta de resultados e PROVA
\end{tabular}

Entre a $1^{\underline{a}}$ e a $2^{\underline{a}}$ aula, os aprendizes organizaram-se em grupos, de acordo com seus EdA. Foram formados grupos tais que aprendizes com EdA semelhantes trabalhassem juntos. Um benefício secundário dessa regra de formação das equipes foi evitar o processo viciado de formação dos mesmos grupos (panelas), o que normalmente ocorre em cursos longos.

A partir da segunda aula, cada grupo de aprendizes assumiu o comando de uma das empresas, que competiram entre si durante entre sete e 10 meses. Cada semana de aula correspondeu a um ciclo de tomada de decisão, que representa um mês de gerenciamento da empresa.

Nas duas últimas aulas, os aprendizes apresentaram para o conselho diretor da empresa os resultados obtidos durante o período da sua gestão. Essa apresentação foi seguida de uma discussão dos resultados agregados da turma em comparação às turmas passadas, para consolidação dos aprendizados.

A avaliação geral na disciplina procurou considerar todas as atividades, além dos resultados no jogo e da nota no teste final de conhecimentos. Baseou-se num conjunto mais abrangente de critérios (Quadro 3) que influenciaram a vivência, mas que não foram considerados neste estudo. Este estudo centrouse na nota da prova final, cujo objetivo foi avaliar o entendimento (assimilação e compreensão) dos conceitos relacionados ao planejamento de produção com o MRP, MRPII e ERP. $O$ índice de acertos nesse conjunto de questões representou a métrica de aprendizagem adotada neste estudo. 
Quadro 3. Critérios de avaliação da disciplina

\begin{tabular}{l|l|l}
\hline CRITÉRIO DE AVALIAÇÃO & DETALHAMENTO & AVALIAÇÃO \\
\hline Desempenho da empresa & $\begin{array}{l}\text { Cada empresa teve seu desempenho avaliado de maneira comparativa segundo os } \\
\text { indicadores de desempenho definidos no estudo de caso: giro de estoques, nível de } \\
\text { serviço, completude do plano de produção e lucro líquido }\end{array}$ & Grupo \\
\hline Resumos das leituras & $\begin{array}{l}\text { A cada aula, os estudantes entregaram individualmente um resumo da leitura do } \\
\text { capítulo que seria discutido na aula }\end{array}$ & Individual \\
\hline Indicador de desempenho & $\begin{array}{l}\text { Cada integrante do grupo de gestão foi responsável por um indicador de desempenho e } \\
\text { foi avaliado por seu desempenho }\end{array}$ & Individual \\
\hline Distribuição de lucro & $\begin{array}{l}\text { Ao final de cada trimestre de simulação, os estudantes fizeram a distribuição dos lucros } \\
\text { acumulados segundo critério escolhido pela empresa }\end{array}$ & Individual \\
\hline Apresentação para Conselho & $\begin{array}{l}\text { Os conselheiros avaliaram a capacidade que os gestores tiveram de explicar o } \\
\text { desempenho da empresa durante seu período de gestão }\end{array}$ & Grupo \\
\hline Prova & Prova conceitual & Individual \\
\hline
\end{tabular}

As ANOVA conduzidas para identificar diferenças aprendizado segundo os EdA, inicialmente, foram feitas agrupando os estudantes do dois cursos e, na sequência, separando-os por curso.

Na primeira análise, foram suprimidos os aprendizes com as preferências forte-reflexivo, forte-verbal, moderada-verbal, forte-intuitivo, forte-sequencial e forte-geral, por conta da pequena quantidade de aprendizes com essas preferências. Na segunda análise, quando foram separados por curso (Logística e MBA), houve uma diminuição dos dados em cada um dos EdA. Para lidar com essa limitação, os dados de preferência moderada e forte foram agregados numa classe única para as quatro dimensões do EdA.

\section{ANÁLISE DESCRITIVA DOS DADOS}

Antes de avaliar os principais resultados dessa pesquisa, cabe apresentar alguns dados que qualificam o perfil dos estudante das disciplinas. No início do curso, eles tinham, em média, 30,3 anos de idade e 4,4 anos de experiência profissional. No MBA, a idade média foi 32,3 anos e, no curso de Logística, 28,7. 0 tempo de experiência era de 5,3 anos no MBA e 3,8 no curso de Logística. No geral, as três principais fontes de estudantes foram Administração de Empresas (53\%), Engenharia (27\%) e Tecnólogos (8\%). No MBA, essa proporção foi: Administração de Empresas (39\%), Engenharia (39\%) e Tecnólogos (6\%). No curso de Logística, observou-se: Administração de Empresa (68\%), Engenharia (15\%) e Tecnólogos (11\%).

A análise dos EdA dos 356 aprendizes apresentou uma presença heterogênea de cada tipo. Como se observa na Figu- ra 6, os estudantes dividiram-se em: $40 \%$ ativos (moderado ou forte), $5 \%$ reflexivos e $55 \%$ sem preferência. Na dimensão sensorial-intuitivo, $42 \%$ indicaram preferência sensorial, $54 \%$ sem preferência e $4 \%$ com preferência no estilo intuitivo (moderada ou forte). Para o estilo visual-verbal, 59\% tinham preferência visual ( $23 \%$ visual forte e $37 \%$ moderada), $38 \%$ sem preferência e 3,0\% preferência verbal. No estilo sequencial-geral, o resultado foi $19 \%$ com preferência sequencial, $63 \%$ sem preferência e $18 \%$ com preferência geral.

$\mathrm{Na}$ Tabela 1, encontra-se a quantidade de estudantes em cada EdA para as quatro dimensões, bem como as médias e desvios padrão das notas da prova. A Figura 6 também apresenta as médias das notas com intervalos de confiança de $95 \%$ para cada estilo de aprendizagem. Na análise gráfica, é possível antecipar o resultado do teste de médias, que indicou diferença significativa de aproveitamento na prova segundo as preferências nas dimensões ativo-reflexivo $(F(3,349)=3.83$; $p=0,01)$ e visual-verbal $(F(2,343)=4.61 ; p=0,011)$. Não se observaram diferenças de aprendizagem nas dimensões sensorial-intuitivo e sequencial-geral. Os resultados detalhados são apresentados na Tabela 2. Para ambas as dimensões, observou-se homogeneidade das variâncias pelo teste de Levene. 0 resultado do teste a posteriori de Tukey indicou diferença significativa entre as notas dos aprendizes, com:

- Preferência reflexiva-moderada com média 7,9 em relação aos aprendizes com preferência ativa moderada e forte, cujas médias foram 6,4 e 6,3, respectivamente; e

- Preferência visual-forte e visual-moderada, cujas médias foram iguais a 6,8 , em relação aos aprendizes sem preferência visual, cuja média foi de 6,3. 
Figura 6. Estilos de aprendizagem (ILS) dos aprendizes e comparação das notas na avaliação
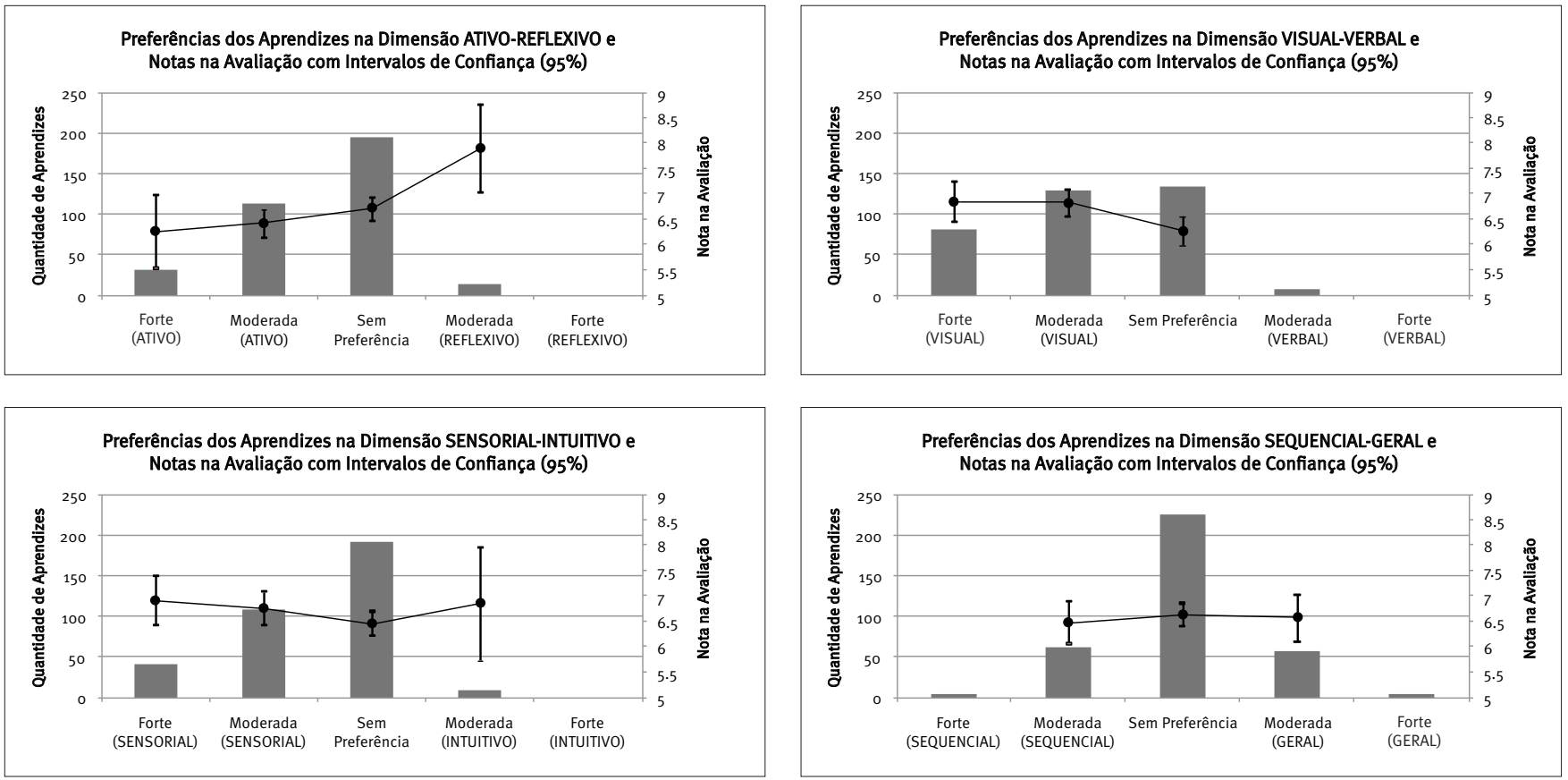

TABELA 1. Notas dos aprendizes por estilo de aprendizagem

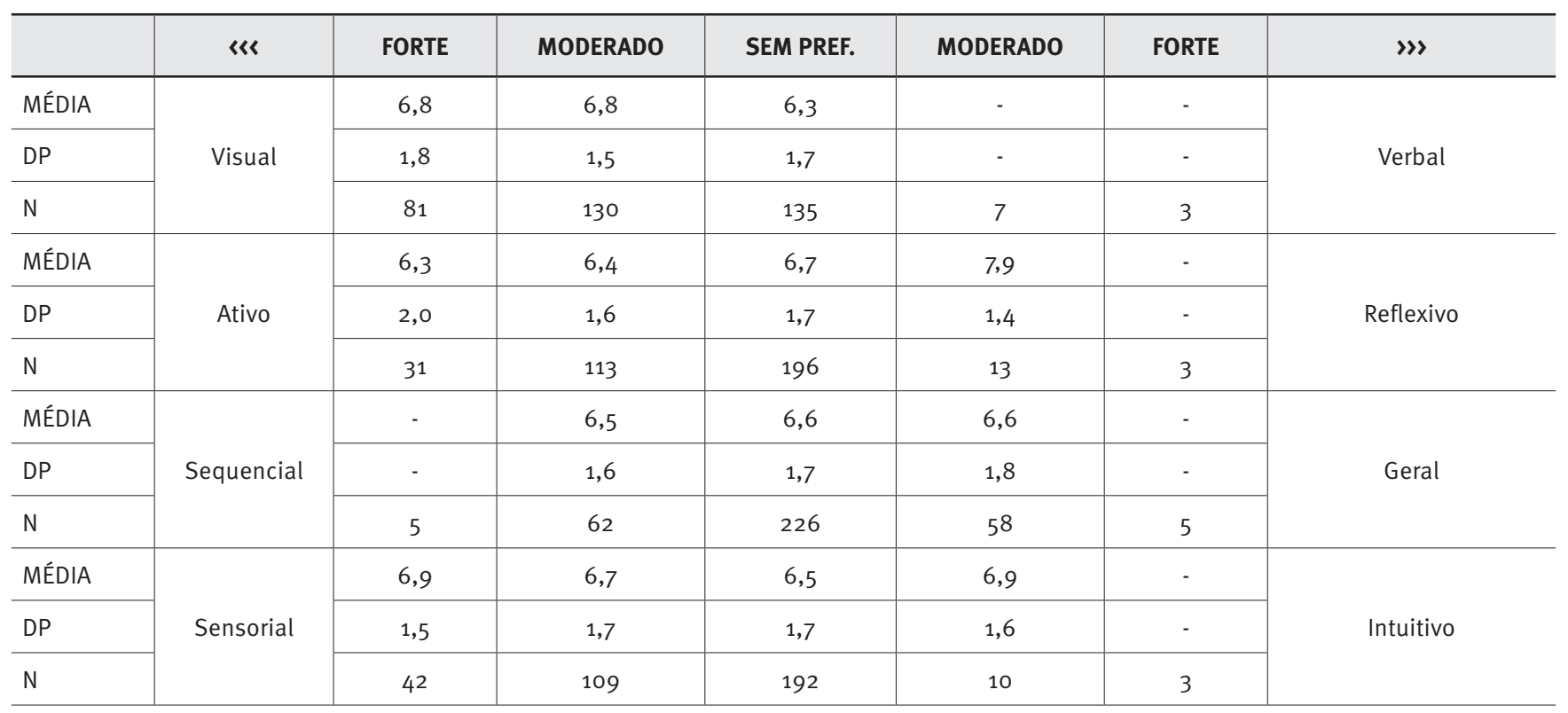

\section{TABELA 2. Teste de médias para as notas dos aprendizes por estilo de aprendizagem}

\begin{tabular}{l|c|c|c}
\hline EdA & F & P & RESULTADO \\
\hline Visual-Verbal & $\mathrm{F}(2,343)=4,61$ & 0,011 & \multirow{2}{*}{ Rejeita-se a hipótese de igualdade entre as médias } \\
\cline { 1 - 2 } Ativo-Reflexivo & $\mathrm{F}(3,349)=3,83$ & 0,010 & \multirow{2}{*}{ Não se rejeita a hipótese de igualdade entre as médias } \\
\cline { 1 - 2 } Sequencial-Geral & $\mathrm{F}(2,343)=0,24$ & 0,788 & \\
\cline { 1 - 2 } Sensorial-Intuitivo & $\mathrm{F}(3,349)=1,31$ & 0,271 &
\end{tabular}


Na Tabela 3, apresentam-se as médias e os desvios padrão das notas na prova do estudantes separados por EdA e por curso. Essas médias, bem como a quantidade de estudantes, também podem ser observadas na Figura 7, que apresenta ainda os intervalos de confiança (95\%) das médias na nota da prova. Observaram-se, no curso de Logística (Tabela 4), diferenças entre as médias nas dimensões ativo-reflexivo, com as médias crescentes de 6,3 para os ativos, 6,7 para os sem preferência e 7,4 para os reflexivos. Na dimensão visual-verbal, as médias foram de 6,8 para os visuais e 6,2 para os sem preferência visual ou verbal. Finalmente, a terceira dimensão, que apresentou di- ferença significativa entre as médias no curso de Logística, foi a sensorial-intuitivo. Os sensoriais tiveram a média de 6,9 e os sem preferência ficaram com 6,3. No MBA, não houve diferença significativa em qualquer dimensão dos EdA. Apesar de ser possível verificar, visualmente, na Figura 7 , um perfil de variação semelhante no aproveitamento médio dos aprendizes nas três primeiras dimensões (ativo-reflexivo, visual-verbal e sensorial-intuitivo), as variâncias das notas dos estudantes do MBA foram significativamente superiores às do curso de Logística, o que levou à aceitação das hipóteses de igualdade das médias nos testes estatísticos realizados.

\section{TABELA 3. Notas dos aprendizes por estilo de aprendizagem e por curso}

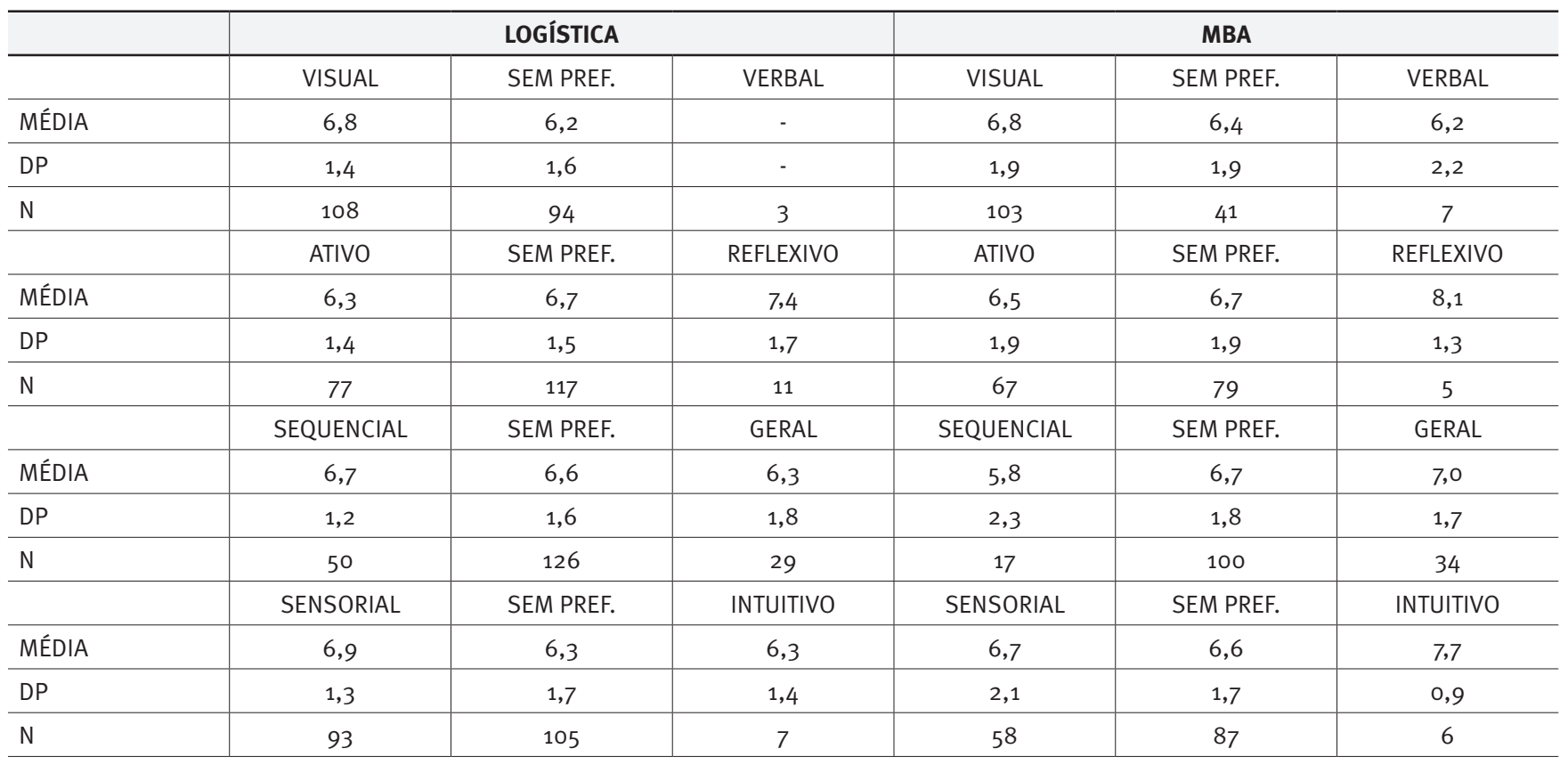

TABELA 4. Teste de médias para as notas dos aprendizes por estilo de aprendizagem e por curso

\begin{tabular}{|c|c|c|c|c|}
\hline & EdA & $\mathbf{F}$ & $\mathbf{P}$ & RESULTADO \\
\hline \multirow{3}{*}{$\stackrel{\nwarrow}{\stackrel{\varpi}{\Sigma}}$} & Ativo-Reflexivo & $\mathrm{F}(2,148)=1,83$ & 0,164 & \multirow{3}{*}{ Não se rejeita a hipótese de igualdade entre as médias } \\
\hline & Sequencial-Geral & $F(2,148)=2,68$ & 0,072 & \\
\hline & Sensorial-Intuitivo & $F(2,148)=0,96$ & 0,384 & \\
\hline \multirow{3}{*}{ 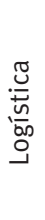 } & Ativo-Reflexivo & $F(2,202)=3,19$ & 0,043 & Rejeita-se a hipótese de igualdade entre as médias \\
\hline & Sequencial-Geral & $F(2,202)=0,61$ & 0,546 & Não se rejeita a hipótese de igualdade entre as médias \\
\hline & Sensorial-Intuitivo & $F(2,202)=3,56$ & 0,030 & Rejeita-se a hipótese de igualdade entre as médias \\
\hline
\end{tabular}

Pode-se observar que as turmas do MBA são mais heterogêneas no que diz respeito à compreensão dos conceitos avaliados pela prova final da disciplina. Entretanto, de modo geral, não se pode observar diferença significativa do aproveitamento quando comparado o desempenho médio de estudantes do MBA e do curso de Logística $(F(1,354)=0,32 ; p=0,57)$. 
Figura 7. Estilos de aprendizagem (ILS) dos aprendizes e comparação das notas na avaliação organizados por curso
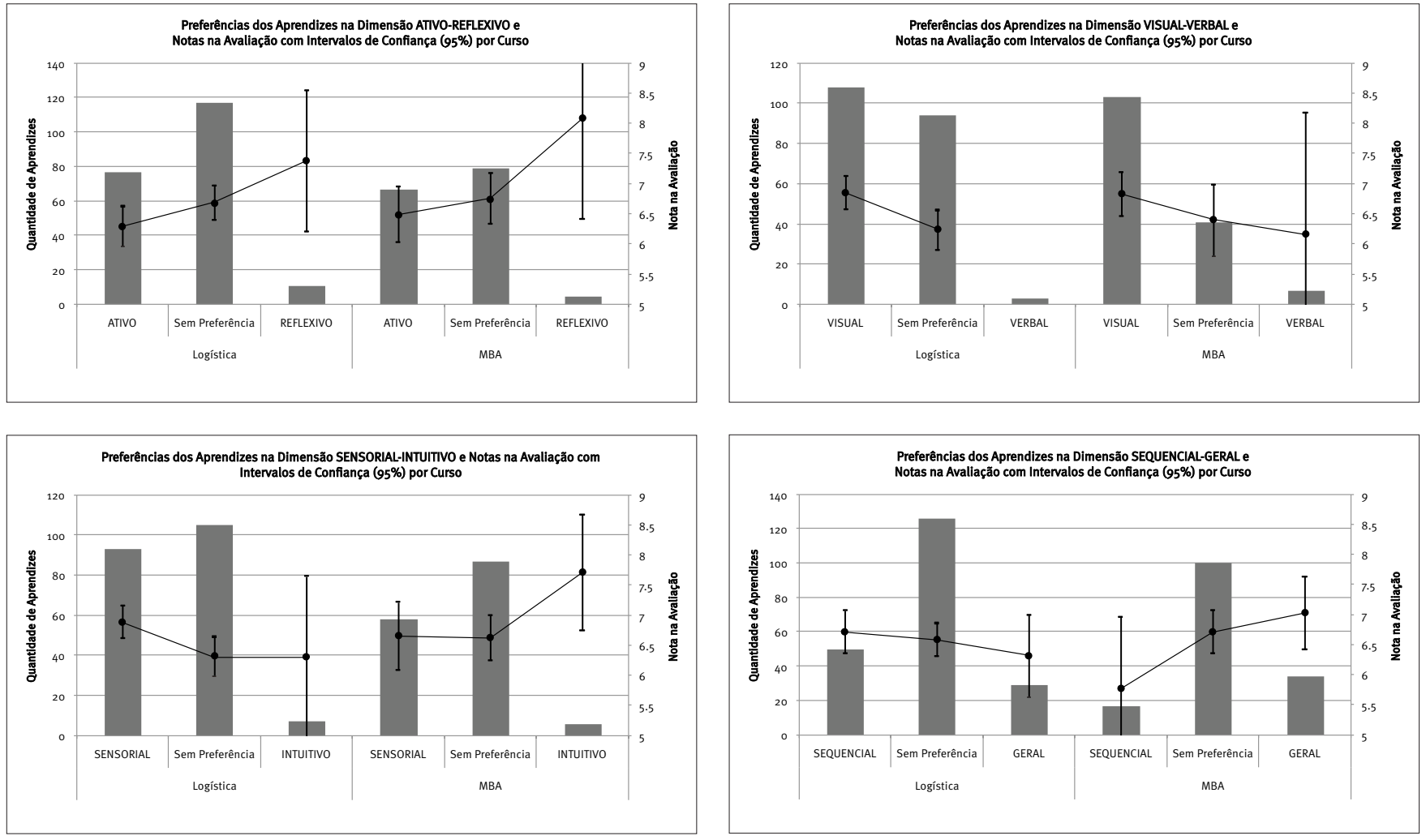

\section{DISCUSSÃO DOS RESULTADOS}

0 aproveitamento superior dos aprendizes com preferência visual está em consonância com a linguagem imposta pelo conteúdo das disciplinas. No desenrolar do jogo, o aprendiz precisa aplicar a ferramenta de planejamento de materiais para gerir a empresa Politron. 0 registro básico do MRP (Figura 1) representa visualmente, na forma de um diagrama, o fluxo de materiais e as decisões planejadas. Para sua compreensão e aplicação, é importante que o aprendiz perceba visualmente e interprete as informações esquematizadas no registro. 0 conteúdo do MRP parece ter sido formatado para fácil assimilação dos aprendizes com o estilo visual, aqueles que, segundo Felder e Silverman (1988), melhor memorizam o que veem em figuras, diagramas, fluxogramas, filmes e demonstrações.

$\mathrm{Na}$ dimensão sensorial-intuitivo, ao considerarmos que os sensoriais aprendem mais pela experimentação, o método de ensino empregado na disciplina com jogos de empresa já cria, de partida, oportunidades de aprendizado preferidas pelos sensoriais. Foi observado aproveitamento significativamente superior dos sensoriais no curso de Logística, com uma média de 6,9 , ao passo que os estudantes sem preferência tiveram média de 6,3.

Para o estilo ativo-reflexivo, houve uma diminuição da média no sentido do estilo ativo-forte, com as seguintes médias: reflexivo-moderado: 7,9; sem preferência: 6,7; ativo-moderado: 6,4; ativo-forte: 6,3. Esse resultado encontra suporte nos resultados observados por Dias, Sauaia e Yoshizaki (2008, p. 9), com uso de jogos de empresa na pós-graduação em Administração, e Silva (2006), com disciplinas ativas em curso de graduação em Contabilidade.

$\mathrm{Na}$ interpretação, procurou-se explicar as diferenças de aprendizado analisando-se as proposições de Felder e Silverman (1988, p. 678) quanto aos métodos de ensino mais indicados para cada EdA. Ao definirem o estilo ativo-reflexivo, os autores basearem-se nos conceitos de "experimentação ativa" e “observação reflexiva” de Kolb (1984). Assim, ativos são os que preferem a experimentação ativa e reflexivos preferem a observação reflexiva. 0 fato de os ativos-fortes terem o pior aproveitamento pareceu contraditório, visto que os jogos de empresas atendem as preferências de aprendizes ativos. Isso pode ser constatado ao considerar-se que a vivência nas disciplinas descritas neste estudo incorporou, em grande medida, as "boas práticas educacionais" para os ativos, listadas no Quadro 4, segundo Felder e Silverman (1988, p. 680).

Para interpretar os dados observados, lançou-se mão da teoria de aprendizagem vivencial de Kolb (1984, p. 42). Segun- 
do ele, o processo de aprendizagem vivencial depende de todas as etapas do ciclo: vivência concreta, observação reflexiva, conceitualização abstrata e experimentação ativa. Pode-se supor que o aproveitamento decrescente, quanto mais ativa foi a preferência do estudante, tenha decorrido da carência por atividades que estimulassem a observação reflexiva. A disciplina predominantemente ativa, na forma como o jogo foi conduzido, propicia mais oportunidades de transformação do conhecimento pela experimentação ativa (extroversão). Nessas etapas do jogo, os reflexivos, que preferem a transformação do conhecimento pela observação reflexiva (introspecção), são forçados a experimentar ativamente os conhecimentos já compreendidos. Dessa forma, os reflexivos aproveitam para fechar o ciclo de aprendizagem vivencial de maneira mais efetiva que os ativos. De um lado, fazendo valer suas preferências pessoais, e, do outro, com as situações que lhes são impostas pela experiência projetada pelo professor com o jogo. Esse raciocínio está representado visualmente na Figura 8, com o exemplo de uma disciplina ajustada para as preferências dos ativos, mas não para sua melhor aprendizagem.

Se, por um lado, os aprendizes ativos encontraram nas disciplinas oportunidades para vivenciar suas preferências ativas do outro, as práticas educacionais sugeridas para aprendizes reflexivos (Quadro 4) não ocorrem obrigatoriamente durante a tomada das decisões. Na linguagem dos jogos de empresa, como definido por Sauaia (2010), é possível que a vivência se desenrole sem que a atividade de avaliação dos resultados (observação reflexiva) efetivamente ocorra. Os aprendizes parecem não ter encontrado na disciplina uma mecânica que os conduzisse ou que idealmente garantisse a realização dos processos de observação reflexiva (introspecção). Dessa forma, os estudantes mais ativos podem ter tido maior dificuldade para transformar reflexivamente o conhecimento percebido, o que, consequentemente, prejudicaria sua compreensão.

\section{Figura 8. Ciclo de KOLB com lacuna na observação reflexiva}

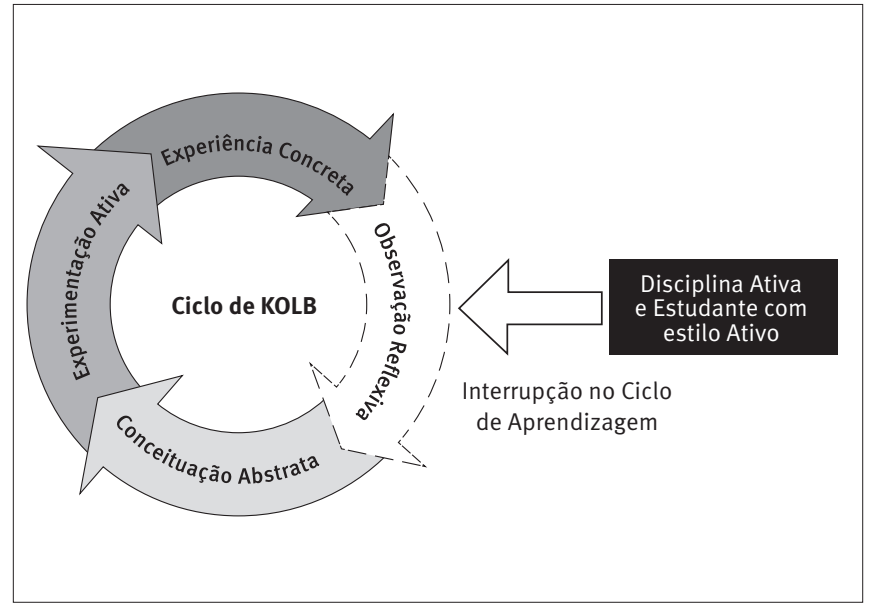

\section{Quadro 4. Práticas educacionais sugeridas para aprendizes ativos e reflexivos}

\section{APRENDIZES ATIVOS}

Dar ênfase no material do curso para solução de problemas práticos

Utilizar treinamento prático, quando possível

Adotar método instrucional assistido por computador

Proporcionar oportunidades para o aprendiz fazer algo ativo, além de escrever

Atribuir exercícios de aplicação para proporcionar a prática do que está sendo ensinado

Dar aos aprendizes a opção de trabalhar em grupo nos trabalhos de casa na maior medida possível

\section{APRENDIZES REFLEXIVOS}

Dar ênfase no material do curso para o entendimento dos fundamentos

Fornecer breves intervalos durante a aula para que os aprendizes pensem sobre o que foi dito

Fornecer problemas abertos e exercícios que exijam atividades de análise e síntese

Fonte: FELDER e SILVERMAN, 1988. 


\section{CONCLUSÕES}

O objetivo central da pesquisa foi estudar de maneira descritiva as variações de aprendizado nas disciplinas de PCP (para o ensino de MRP, MRPII e ERP com jogos de empresas) decorrentes dos EdA dos estudantes. Os resultados indicaram diferenças significativas associadas ao EdA e sinalizaram indícios que confirmam observações teóricas de que não basta focar o desenho de uma disciplina para determinado EdA.

Com base nas referências teóricas e nos dados primários observados neste estudo descritivo, sugere-se que os agentes de aprendizagem, dirigentes de IES, educadores e os próprios estudantes, ao elaborarem seus planos de ensino e de aprendizagem, atentem para procedimentos que considerem 0 caráter cíclico da aprendizagem vivencial, como proposto por Kolb (1984), e que criem oportunidades de aprendizagem de maneira balanceada para todos os EdA, em concordância com as sugestões de Felder e Spurlin (2005), Seno e Belhot (2009) e Felder (2010).

Quando utilizados os jogos de empresas, corre-se um risco adicional no processo de aprendizagem: quanto mais ativo o aprendiz, maior o risco de ele não fechar o ciclo de aprendizagem por falta de atividades reflexivas. Aos educadores que já adotam métodos predominantemente ativos, ressalta-se a importância dos momentos de convite à reflexão nos quais os aprendizes, sobretudo os ativos, sejam estimulados a analisarem os resultados das rodadas no jogo e fazerem observações reflexivas para fechar seu ciclo de aprendizagem vivencial.

Cabe, aqui, sugerir uma possível complementação à síntese de Mintzberg e Gosling (2003, p. 29) para o processo de educação gerencial: "As aulas de educação em gestão devem ser ambientes em que os administradores possam refletir profundamente sobre sua experiência" com "especialmente para estudantes ativos".

\section{LIMITAÇÕES E SUGESTÕES}

Como estudo descritivo, ressalta-se que a generalização das conclusões é limitada. Os resultados sugerem relações que podem ser utilizadas em estudos futuros. Além disso, alguns EdA do modelo utilizado apresentaram reduzida quantidade de aprendizes na amostra estudada. Para aumentar a abrangência das análises, recomenda-se replicar o estudo com amostras que tenham mais aprendizes com estilo reflexivo-forte.

Outra limitação é a métrica utilizada na mensuração do aproveitamento (a nota em um teste de conhecimentos) que decorreu da arbitrariedade dos autores. Apesar de a prova rela- cionar-se aos objetivos específicos de aprendizado da disciplina, ela é um instrumento limitado de avaliação do aprendizado. Para novos estudos e maior alcance das conclusões, sugere-se considerar o uso de outras formas de avaliação de aprendizado.

Nos últimos anos, o Brasil tem passado por um processo de massificação dos cursos de formação superior. Ainda existem desafios a serem vencidos no acesso à formação superior. Entretanto, são urgentes iniciativas que tratem da efetiva aprendizagem nesse ambiente de massificação. Com o apoio da tecnologia de informação e das teorias de aprendizagem, os jogos de empresa propiciam uma oportunidade de customização massificada do processo de aprendizagem, tornando-o mais eficaz. Este estudo procura contribuir com o avanço desse conhecimento.

Espera-se que este estudo possa colaborar com pesquisas futuras voltadas para a ação dos agentes de aprendizagem na construção de planos de ensino e de aprendizagem que levem em conta a individualidade de cada estudante, sobretudo com a adaptação dos métodos instrucionais à diversidade de EdA.

\section{Nota da Redação}

Este artigo foi apresentado no XV Simpósio de Administração da Produção, Logística e Operações Internacionais em 2012, organizado pelos professores Luiz Artur Ledur Brito, Antônio Domingos Pádula e Gérson Tontini, promovido pelo Departamento de Administração da Produção e de Operações da Escola de Administração de Empresas de São Paulo, Fundação Getulio Vargas.

\section{REFERÊNCIAS}

COFFIELD, F; MOSELEY, D; HALL, E; ECCLESTONE, K. Learning styles and pedagogy in post-16 learning: a systematic and critical review. London: Learning and Skills Research Centre, 2004. $173 \mathrm{p}$.

COOK, D. A; THOMPSON, W. G; THOMAS, K. G; THOMAS, M. R. Lack of interaction between sensing-intuitive learning styles and problem-first versus information-first instruction: a randomized crossover trial. Advances in Health Sciences Education, v. 14, n. 1, p. 79-90, 2009.

CORRÊA, H. L. O uso de simulação para a educação e treinamento em gestão com sistema ERP. In: SIMPÓSIO DE PRODUÇÃO E OPERAÇÕES INTERNACIONAIS, 2, 1999, São Paulo. Anais. São Paulo: SIMPOI, 1999.

CORRÊA, H. L; GIANESI, I. G. N; CAON, M. Planejamento, programação e controle da produção MRPII/ERP: conceitos, uso e implantação. 5. ed. São Paulo: Atlas, 2007. 456 p.

CURRY, L. A critique of the research on learning styles. Educational Leadership, v. 48, n. 2, p. 50-56, 1990.

DEWEY, J. Experience \& education. 1938. Disponível em: http://ruby. fgcu.edu/courses/ndemers/colloquium/experienceducationdewey. pdf. Acesso em 21.07.2012. 
DIAS, G. P. P; SAUAIA, A. C. A; YOSHIZAKI, H. T. Y. Estilos de aprendizagem e o aproveitamento em jogos de empresas: um estudo descritivo. In: SIMPÓSIO DE ADMINISTRAÇÃO DA PRODUÇÃO, LOGÍSTICA E OPERAÇÕES INTERNACIONAIS, 11, 2008, São Paulo. Anais. São Paulo: SIMPOI, 2008.

FARIA, A. J. The changing nature of business simulation/gaming research: a brief history. Simulation \& Gaming, v. 32, n. 1, p. 97-110, 2001.

FELDER, R. M; SILVERMAN, L. K. Learning and teaching styles in engineering education. Engineering Education, v. 78, n. 7, p. 674-681, 1988.

FELDER, R. M; SOLOMAN, B. A. Learning styles and strategies. 1991. Disponivel em: http://www4.ncsu.edu/unity/lockers/users/f/felder/public/ILSdir/styles.htm. Acesso em 24.02.2012.

FELDER, R. M; SPURLIN, J. Applications, reliability and validity of the index of learning styles. International Journal on Engineering Education, $v$. 21, n. 1, p. 103-112, 2005

FELDER, R. M. Are learning styles invalid? (Hint: no!). On-Course Newsletter, 2010. Disponivel em: http://www4.ncsu.edu/unity/lockers/ users/f/felder/public/Papers/LS_Validity(On-Course).pdf. Acesso em 24.02.2012.

GRAF, S; VIOLA, S. R; LEO, T; KINSHUK. In-depth analysis of the Felder-Silverman learning style dimensions. Journal of Research on Technology in Education, v. 40, n. 1, p. 73-93, 2007. Disponivel em: http://www.scielo.br/scielo.php?script=sci_pdf\&pid=S1413-23112012000200002\&l$\mathrm{ng}=\mathrm{en} \& \mathrm{nrm}=\mathrm{iso} \& \mathrm{t} \mathrm{ng}=\mathrm{pt}$. Acesso em 24.02.2012

HSIEH, S. W; JANG, Y. R; HWANG, G. J; CHEN, N. S. Effects of teaching and learning styles on students' reflection levels for ubiquitous learning. Computers \& Education, v. 57, n. 1, p. 1194-1201, 2011.

KAYES, D. C. Experiential learning and its critics: preserving the role of experience in management learning and education. Academy of Management Learning \& Education, v. 1, n. 2, p. 137-149, 2002.

KEYS, B; BIGGS, W. A review of business games. In: Gentry J. W. (Coord) Guide to business gaming and experiential learning. East Brunswick, NJ: Nichols/GP, 1990. p. 48-73.

KOH, S. C. L; GUNASEKARAN, A; RAJKUMAR, D. ERPII: the involvement, benefits and impediments of collaborative information sharing. International Journal of Production Economics, v. 113, n. 1, p. 245-268, 2008

KOLB, D. Experiential learning: experience as the source of learning and development. Englewood Cliffs: Prentice-Hall, 1984. 256 p.

LITZINGER, T. A; LEE, S. H; WISE, J. C; FELDER, R. M. A psychometric study of the index of learning styles. Journal of Engineering Education, v. 96, n. 4, p. 309-319, 2007.
MINZTBERG, H; GOSLING, J. Educando administradores além das fronteiras. RAE-Revista de Administração de Empresas, v. 43, n. 2, p. 29-43, 2003.

PAES DE PAULA, A.P.; RODRIGUES, M.A. Pedagogia crítica no ensino da administração: desafios e possibilidades. In: ENCONTRO NACIONAL DA ASSOCIAÇÃO NACIONAL DOS PROGRAMAS DE PÓS-GRADUAÇÃO EM ADMINISTRAÇÃO, 30, 2006, Salvador. Anais. Salvador: ANPAD, 2006.

PASHLER, H; MCDANIEL, M; ROHRER, D; BJORK, R. Learning styles: concepts and evidence. Psychological Science in the Public Interest, v. 9, n. 3, p. 105-119, 2008.

SAUAIA, A. C. A. Satisfação e aprendizagem em jogos de empresas: contribuições para a educação gerencial. 1995. 273 p. Tese de Doutorado em Administração, Faculdade de Economia, Administração e Contabilidade da Universidade de São Paulo, São Paulo, 1995.

SAUAIA, A. C. A. Monografia racional. In: SEMINÁRIOS EM ADMINISTRAÇÃO, 1, 1996, São Paulo. Anais. São Paulo: SEMEAD, 1996. p. 276294 .

SAUAIA, A. C. A. Conhecimento versus desempenho das organizações: um estudo empírico com jogos de empresas. REAd-Revista Eletrônica de Administração, v. 12, n. 1, 2006.

SAUAIA, A. C. A. Laboratório de gestão: simulador organizacional, jogo de empresas e pesquisa aplicada. 2. ed. Barueri: Manole, 2010. 256 p.

SCHWAHN, C; MCGARVEY, B. Inevitable: mass customized learning, learning in the age of empowerment. Independent Publishing, 2012. $231 \mathrm{p}$.

SENO, W. P; BELHOT, R. V. Delimitando a fronteira para a identificação de competências para a capacitação de professores de engenharia para o ensino a distância. Gestão \& Produção, v. 16, n. 3, p. 502-514, 2009.

SILVA, D. M. 0 impacto dos estilos de aprendizagem no ensino de contabilidade da FEA-RP/USP. 2006. 169 p. Dissertação de Mestrado em Contabilidade, Faculdade de Economia, Administração e Contabilidade de Ribeirão Preto da Universidade de São Paulo, São Carlos, 2006.

SUGAR, S; WHITCOMB, J. Training games. Alexandria: Amer Society for Training \& Development, 2006. 128 p.

VAN ZWANENBERG, N; WILKINSON, L. J; ANDERSON, A. Felder and Silverman's index of learning styles and Honey and Mumford's learning styles questionnaire: how do they compare and do they predict academic performance? Educational Psychology, v. 20, n. 3, p. 365-380, 2000. 